Daniel Aubram

\title{
Development and experimental validation of an arbitrary Lagrangian-Eulerian (ALE) method for soil mechanics
}

Journal article | Accepted manuscript (Postprint)

This version is available at https://doi.org/10.14279/depositonce-9147

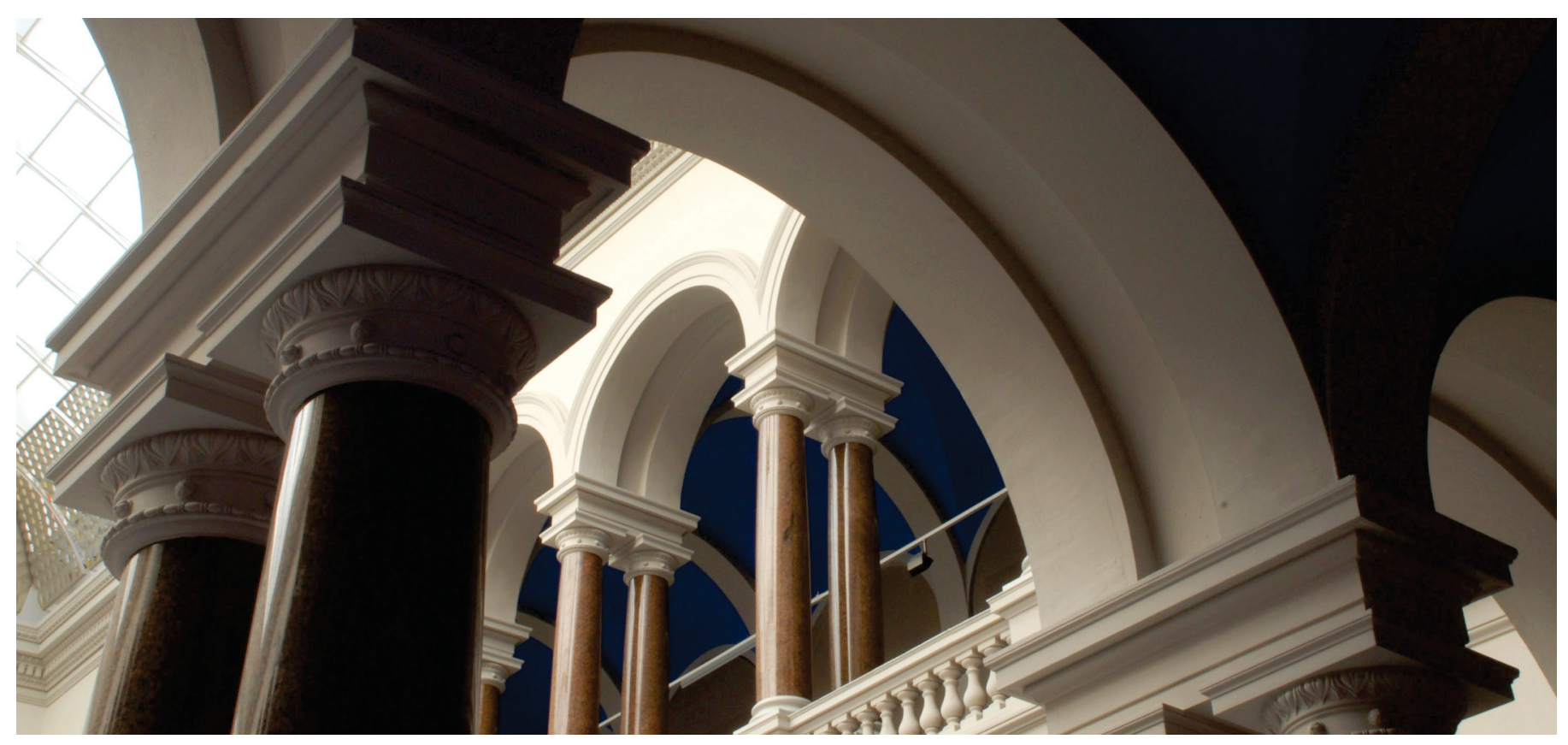

This is the peer reviewed version of the following article:

Aubram, D. (2015). Development and experimental validation of an arbitrary Lagrangian-Eulerian (ALE) method for soil mechanics. Geotechnik, 38(3), 193-204. https://doi.org/10.1002/gete.201400030

which has been published in final form at https://doi.org/10.1002/gete.201400030. This article may be used for non-commercial purposes in accordance with Wiley Terms and Conditions for Use of SelfArchived Versions. 


\section{Development and experimental validation of an arbitrary Lagrangian-Eulerian (ALE) method for soil mechanics}

Large deformation problems in soil mechanics and geotechnical engineering can hardly be addressed by the traditional Lagrangian finite element method because the material and mesh motions coincide. This paper presents an arbitrary Lagrangian-Eulerian (ALE) method in which the computational mesh is regarded as an independent reference domain to keep mesh quality acceptable throughout the calculation. The relative velocity between the material and the mesh introduces additional complexity which is treated by a Lagrange-plus-remap strategy in conjunction with efficient algorithms. Because thorough validation plays a crucial role, experimental model test concerned with penetration into sand have been carried out and back-analyzed by using the ALE method.

Entwicklung und experimentelle Validierung einer allgemeinen Lagrange-Euler (ALE) Methode für Bodenmechanik: Bodenmechanische und geotechnische Problemstellungen mit großen Verformungen können mit der traditionellen Lagrange'schen Finite Elemente Methode kaum gelöst werden, weil hierbei die Bewegung des Netzes der des Materials entspricht. Dieser Beitrag präsentiert eine allgemeine Lagrange-Euler (ALE) Methode, bei der das Netz als unabhängiges Referenzgebiet betrachtet wird, um die Qualiät des Netzes während der gesamten Berechnung aufrecht zu erhalten. Der sich aus der Relativgeschwindigkeit zwischen Material und Netz ergebende Zuwachs an Komplexität wird mittels einer Lagrange-plus-Remap Strategie und effizienten Algorithmen behandelt. Weil die sorgfältige Validierung eine wichtige Rolle spielt, wurden experimentelle Modellversuche zur Penetration in Sand durchgeführt und mit Hilfe der ALE Methode nachgerechnet.

Keywords: arbitrary Lagrangian-Eulerian; large deformations; penetration; sand; validation; model test; große Verformungen; Validierung; Modellversuche

\section{Introduction}

Problems in soil mechanics and geotechnical engineering are often characterized by large material deformations accompanied by an evolution of material interfaces and free surfaces, changing contact conditions, and complex nonlinear material behavior. Examples are slope failure, natural hazards like landslide and earthquake-induced liquefaction, and installation processes including digging, mixing, displacement, or penetration. Such problems can hardly be addressed by the traditional Lagrangian finite element methods (FEM) in which the material and mesh motions coincide. This is because severe element distortions may occur which may slow down or even terminate the calculation. If element distortions become unacceptably large, then a new FE model has to be generated and the solution variables have to be remapped onto the new mesh. This process is called rezoning or adaptive remeshing [1] and constitutes a basic feature in modern nonlinear Lagrangian finite element codes [2].

With the objective to overcome the drawbacks with traditional FEM approaches, advanced numerical modeling and simulation tools received much attention during the past decade, e.g. discrete element methods [3], [4], material point methods [5], [6], smoothed-particle hydrodynamics [7], [8], coupled Eulerian-Lagrange (CEL) methods [2], [9], [10], and arbitrary Lagrangian-Eulerian (ALE) methods [11], [12], [13], [14], [15]. These methods were originally developed in the 1960-70's mostly for applications 
in computational physics and often involve sophisticated non-standard algorithms; see [16] for an overview. Therefore, when applying such complex tools for numerical simulation thorough validation plays a crucial role. Because of their popularity in large deformation analysis of problems in soil mechanics and geotechnical engineering, the differences between Lagrangian FEM with adaptive remeshing (rezoning), CEL, and ALE methods should be briefly addressed here. More detailed discussions can be found in [1],[17].

In ALE methods, the computational mesh is regarded as a reference domain which is not fixed but can move independent of the material at an arbitrary velocity. A Lagrangian method is obtained if the mesh velocity equals the material velocity, whereas a fixed mesh is associated with a Eulerian formulation. The ALE mesh is continuously smoothed by appropriate algorithms such that element distortion is reduced. Since mesh connectivity does not change, the solution variables can be transported through the moving mesh in a conservative manner by making use of advection algorithms from the field of computational fluid dynamics (CFD).

By contrast, a completely new mesh could be generated during rezoning or adaptive remeshing. Since mesh connectivity generally changes, no flux of the solution variables across element boundaries can be calculated. Hence, the remap onto the new mesh has to be established by using interpolation techniques which are generally non-conservative and lead to excessive smearing of solution gradients (numerical diffusion) [1]. If instead the new mesh would be generated from the old mesh by node relocation leaving the connectivity unchanged ( $r$-adaption), then the adaptive remeshing technique can be regarded as an ALE method because node relocation defines mesh motion over a pseudo time increment [17].

Implementations of CEL couple overlapping, but otherwise distinct Eulerian (spatially fixed) and Lagrangian meshes. Usually the Lagrangian mesh discretizes the structure, and the Eulerian mesh covers those regions of space where large material deformations are expected. In contrast to most ALE methods, material boundaries are allowed to flow through the Eulerian mesh such that there no restrictions on the magnitude of deformations. However, this feature is currently restricted to single-phase material (dry or locally undrained soil) and calls for elaborate and computationally expensive algorithms. Moreover, the rigid mesh leads to excessive numerical diffusion which would not be present if the mesh could be adapted to the material motion. The present paper is concerned with the numerical simulation of penetration into sand at large deformations and its validation through experimental model tests. For reasons of simplification we focus on quasi-static plane or axisymmetric penetration into dry sand. Section 2 outlines the governing equations and numerical algorithms of the ALE method developed for this purpose. Results of experimental model tests carried out during the present research are discussed in Section 3. The numerical examples given in Section 4 are concerned with the back-analysis of two tests by using the ALE method.

\section{$2 \quad$ ALE method}

\subsection{Governing equations}

The following section introduces basic equations of ALE continuum mechanics and then outlines the steps of the implemented operator-split ALE finite element solution procedure [15]. A full description is beyond the scope of the paper and is given in [17].

ALE methods are based on a special formulation of continuum mechanics; soil is regarded as a continuum throughout. In the classical description of motion in continuum mechanics, one introduces the material body $\mathcal{B} \subset \mathcal{S}$ and its motion $\varphi_{t}: \mathcal{B} \rightarrow \mathcal{S}$ in the ambient (Euclidian) space $\mathcal{S}$, with time $t \in\left[t_{0}, T\right]$, as shown in Fig. 1. The map $\varphi_{t}$, where $\varphi_{t}(\cdot)=\varphi(\cdot, t)$ is written at $t$ fixed, assigns to material particles $X \in \mathcal{B}$ their current places $x \in \varphi_{t}(\mathcal{B}) \subset \mathcal{S}$. In the ALE description, an arbitrary subset $\mathcal{R} \subset \mathcal{S}$ is called a 
reference domain provided there are a referential motion $\Psi_{t}: \mathcal{R} \rightarrow \mathcal{B}$ and a relative motion $\Phi_{t}: \mathcal{R} \rightarrow \mathcal{S}$ such that the physical motion of the material body can be expressed by

$\varphi_{t}=\Phi_{t} \circ \Psi_{t}^{-1}$

where $\circ$ indicates composition of maps. Clearly, at each instant of time there is a one-to-one correspondence between reference points, particles, and their current places, leading to equivalent descriptions of motion (i.e. ALE, Lagrangian, or Eulerian). We emphasize that $\Psi_{t}$ and $\Phi_{t}$ are differentiable point maps, and not simple coordinate transformations leaving the set of points unchanged; the geometrical background of the ALE description has been introduced in [18]. Differentiation of a motion in time defines a velocity. In particular, the material and mesh velocities are respectively defined through $\boldsymbol{v}_{t} \stackrel{\text { def }}{=}$ $\left(\partial \varphi_{t} / \partial t\right) \circ \varphi_{t}^{-1}$ and $\boldsymbol{w}_{t} \stackrel{\text { def }}{=}\left(\partial \Phi_{t} / \partial t\right) \circ \Phi_{t}^{-1}$, and the difference

$\boldsymbol{c} \stackrel{\text { def }}{=} \boldsymbol{v}-\boldsymbol{w}$

is called the convective velocity. The convective velocity is a fundamental link between the body, its configurations and the reference domain. It denotes the relative velocity between particles and reference points as measured from a point in space. In a purely Lagrangian formulation one has $\boldsymbol{c}=\mathbf{0}$, whereas $\boldsymbol{c}=\boldsymbol{v}$ in a purely Eulerian formulation.

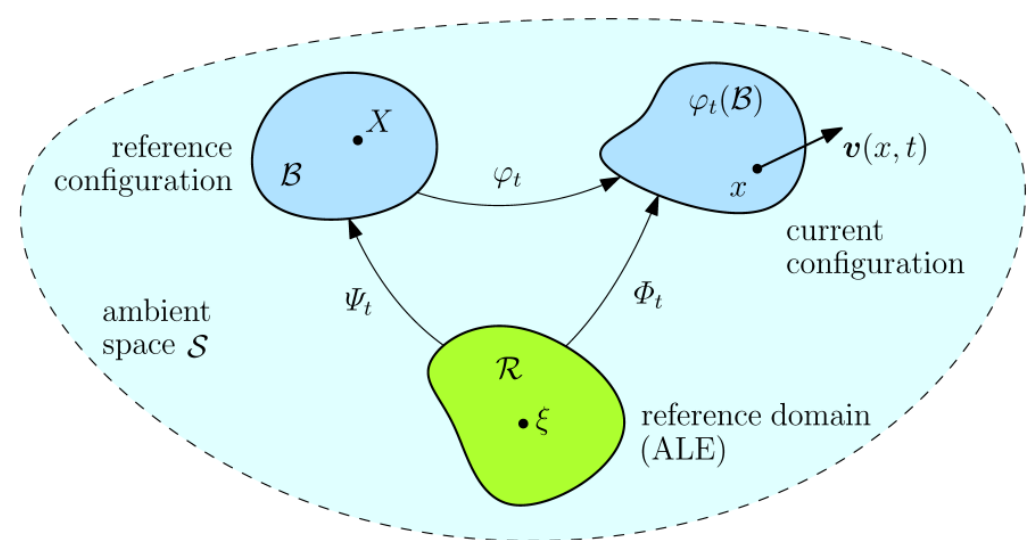

Fig. 1. Continua and mappings related to the Lagrangian, Eulerian, and ALE descriptions

Bild 1. Kontinua und Abbildungen der Lagrange, Euler und ALE Formulierungen

Let $\xi \in \mathcal{R}$ denote the reference points, and let $q(x, t)$, with $x \in \varphi_{t}(\mathcal{B})$, be a time-dependent physical field (Cauchy stress, mass density, etc.). Then, the total time derivative of its so-called referential or ALE description $\hat{q} \stackrel{\text { def }}{=} q \circ \Phi$ resp. $\hat{q}(\xi, t) \stackrel{\text { def }}{=} q(\Phi(\xi, t), t)$ yields the fundamental ALE operator

$\dot{q}=\frac{\partial \hat{q}}{\partial t} \circ \Phi^{-1}+c \cdot \nabla q$

in which $\dot{q}(x, t)$ and $(\nabla q)(x, t)$ are the material time derivative and gradient of $q$ on the ambient space, respectively, and the dot product denotes single contraction of tensors. Note that $\hat{q}$ is the image of $q$ in a different, arbitrarily moving domain of reference, and (3) tells us how the rates of both are related. The definition of the classical material time derivative is obtained for $\boldsymbol{c}=\boldsymbol{v}$ ( $\Phi=$ identity).

The ALE operator (3) is the basic relation to obtain the ALE formulation of the general balance principle:

$\frac{\partial \hat{q} J_{\Phi}}{\partial t}+J_{\Phi}(\operatorname{div}(q \otimes c)) \circ \Phi=J_{\Phi}(S \circ \Phi)$.

Here div is the divergence operator on the ambient space, $J_{\Phi}$ is the Jacobian determinant of the map $\Phi$, and $S$ is the source associated with $q$.Suitable substitutions for $q$ and $S$ lead to particular balance principles. In the present research, the balance principles governing quasi-static penetration into sand are con- 
servation of mass and balance of momentum. The latter involves the Cauchy stress field, whose particular form has to be specified by a constitutive equation.

In the present method, the Cauchy stress is determined by integrating in time a rate constitutive equation taking the general form

$\dot{\boldsymbol{\sigma}}^{\mathrm{ZJ}} \stackrel{\text { def }}{=} \boldsymbol{C}(\boldsymbol{\sigma}, \boldsymbol{h}, \boldsymbol{d}): \boldsymbol{d}$

where $\dot{\boldsymbol{\sigma}}^{\mathrm{ZJ}}=\dot{\boldsymbol{\sigma}}-\boldsymbol{\omega} \cdot \boldsymbol{\sigma}+\boldsymbol{\sigma} \cdot \boldsymbol{\omega}$ is the Zaremba-Jaumann rate of Cauchy stress $\boldsymbol{\sigma}=\boldsymbol{\sigma}^{\mathrm{T}}, \boldsymbol{\omega}=$ $\frac{1}{2}\left(\nabla v-(\nabla v)^{\mathrm{T}}\right)$ is the vorticity of motion, $\boldsymbol{d}=\frac{1}{2}\left(\boldsymbol{\nabla} v+(\nabla v)^{\mathrm{T}}\right)$ is the spatial rate of deformation tensor, $\boldsymbol{h}$ a set of internal material state variables in addition to stress, and $\boldsymbol{C}$ is a fourth-order material tangent tensor. Particular forms of (5) describe the mechanical behavior of the material under consideration. The von-Wolffersdorff hypoplastic rate constitutive equation [19] including the intergranular strain extension [20] is used to simulate the mechanical behavior of sand. In this case $\boldsymbol{h} \stackrel{\text { def }}{=}\{e, \boldsymbol{\delta}\}$, where $e(x, t)$ is the void ratio and $\boldsymbol{\delta}(x, t)$ is the second-order intergranular strain tensor. The implementation of alternative constitutive equations into the ALE method is straightforward as long as they can be represented in the form (5).

\subsection{Numerical implementation}

ALE finite element methods approximate the reference domain $\mathcal{R}$ by a disjoint union of finite elements, and the time interval of interest is approximated by a sequence of discrete time steps. The developed ALE method is based on the operator-split or Lagrange-plus-remap solution strategy [1], which divides (4) into

$\dot{q}=S-q \operatorname{div} v$

and

$\frac{\partial \hat{q} J_{\Phi}}{\partial t}+J_{\Phi}(\operatorname{div}(q \otimes c)) \circ \Phi=0$

The first equation, (6), accounts for the source while the motions of the reference domain and material coincide ( $\boldsymbol{c}=\mathbf{0}$ ), resulting in an (updated) Lagrangian description of motion. The second equation, (7), represents the transport resp. advection of $q$ due to convective velocity $\boldsymbol{c} \neq \mathbf{0}$ and without any external source or material evolution. Accordingly, the operator-split divides the incremental solution in time into a Lagrangian step and a remap step (Fig. 2).

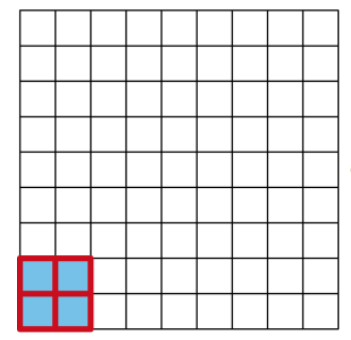

initial configuration

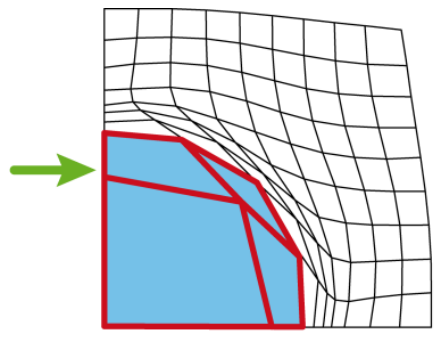

after the Lagrangian step

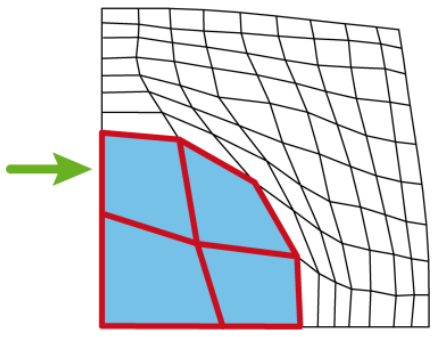

after the remap step

Fig. 2. Schematic diagram of the operator-split ALE method. The blue area indicates a material zone which is assigned to an element patch highlighted in red

Bild 2. Schematische Darstellung der Operator-Split ALE Methode. Die blaue Fläche kennzeichnet eine Materialzone, die einer hier rot umrandeten Elementgruppe zugeordnet ist

The Lagrangian step contains the sources, but convective terms are not present because the mesh follows the material motion. The discretized system of governing equations can thus be advanced in time by almost standard updated Lagrangian finite element procedures for solid mechanical problems [21]. The constitutive equations and evolution equations are integrated over the time step by ensuring incremental 
objectivity at large deformations [22]. Changes in mass density must explicitly be accounted for in order to conserve mass with respect to a moving mesh.

Physical time is "frozen" during the remap step which accounts for the convective terms arising from the relative motion between the body and the reference domain. Conceptually, the remap consists of a mesh motion step and a transport step.

The mesh motion reduces the element distortion occurred during the Lagrangian step through node relocation at fixed mesh connectivity (mesh smoothing). The mesh nodes are processed by applying local smoothing algorithms, and the globally improved mesh is obtained by looping the nodes repeatedly in an iterative fashion. The current implementation of our ALE method relies on a triangle mesh and uses smoothing by weighted averaging for nodes lying on the boundary of the computational domain [23]. A new optimization-based smoothing algorithm has been developed for internal nodes [17], [24]. It determines an approximation to the minimizer of the function

$W(\boldsymbol{x}) \stackrel{\text { def }}{=} \sum_{e l} \frac{R(\boldsymbol{x})}{R_{\mathrm{ref}}}\left(\frac{R(\boldsymbol{x})}{r(\boldsymbol{x})}\right)^{3}$

through an optimization procedure. Here $x \in \mathbb{R}^{2}$ is the position of the internal node, $e l$ is the number of elements in the group of elements sharing the internal node $\boldsymbol{x}, r$ and $R$ are the incircle and circumcircle radius of a triangle element, respectively, and $R_{\text {ref }}=1$ is a reference radius.

The transport step, which is the last step in a calculational cycle of the ALE method, has more in common with computational fluid dynamics than with solid mechanics. A conservative advection scheme is applied which numerically solves the integral form of (7), viz.

$\frac{\mathrm{d}}{\mathrm{d} t} \int_{\mathcal{V}(t)} q \mathrm{~d} v+\int_{\partial \mathcal{V}(t)} q \boldsymbol{c} \cdot \boldsymbol{n} \mathrm{d} a=0$

by using a finite volume discretization [25], where $q \in\{\rho, \boldsymbol{\sigma}, \boldsymbol{h}\}$ and $\mathcal{V}(t)$ is a time-dependent control volume. In this discretization, the approximation to the second term on the left side of (9), representing the flux of $q$ across the control volume boundary, plays a crucial role. A weighted donor-cell flux function [1] is used in the present research.

\section{Experimental model tests}

\subsection{General remarks}

Experimental model tests have been designed and carried out during the present research with the primary intention to deliver information about the phenomenology of penetration into sand which is accessible for back-analysis [17]. The tests involve the quasi-static penetration of a model foundation and model piles with different pile tips in chambers filled with air-dried sand at different initial densities. The foundation and the piles are pressed into the sand along an observing window so that the generated flow field in that plane can be digitally photographed. A method based on particle image velocimetry (PIV) is then applied to measure incremental deformation (instantaneous velocity) and incremental strains by crosscorrelating the image sequences recorded.

Attention is paid mainly to the qualitative rather than quantitative experimental analysis of penetration into sand; the latter is extensively studied in [26], [27], [28]. Moreover, no attempts have been made to reproduce penetration processes associated with foundations, piles, or sounding tools in the field, or to correlate the obtained results with these. As a consequence, no scale models or other similitude theoretical issues need to be considered.

\subsection{Test equipment and PIV measurement}


Two different experimental set-ups have been used: one for the shallow penetration of a model foundation and another for the penetration of model piles. The test chamber for shallow penetration (SP) shown in Fig. 3 on the left is a welded assembly of steel plates. The front plate is equipped with a centered $700 \mathrm{~mm} \times 350 \mathrm{~mm}$ viewing window. A wooden rectangular cuboid with a breadth of $B=150 \mathrm{~mm}$ serves as a model foundation and approximately ensures plane strain conditions in the filling of the chamber. The jack-in device for the foundation is a hydraulic cylinder in conjunction with a two-speed hand pump. Mechanical dial gauge displacement sensors were mounted onto the chamber to measure the vertical displacement of the model foundation, and a force transducer measured the penetration force.

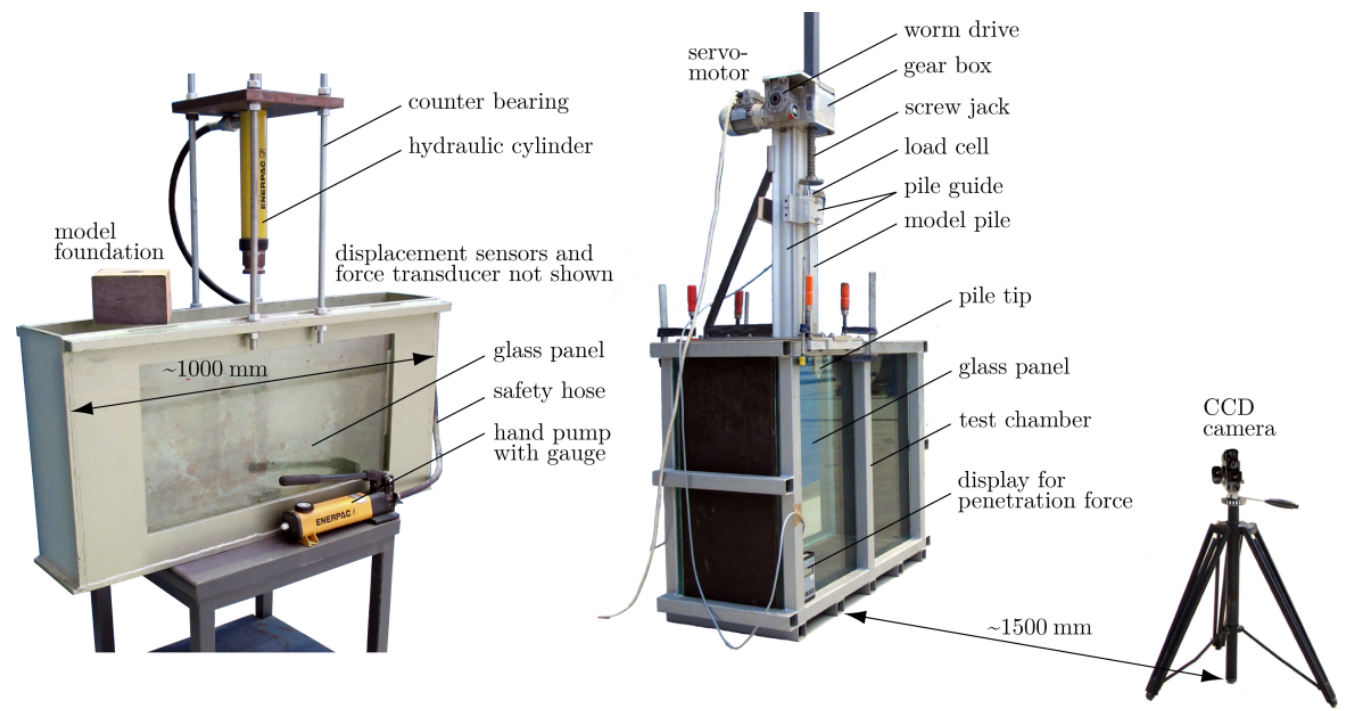

Fig. 3. Experimental set-up for penetration into sand. Left: shallow penetration (SP tests), right: pile penetration (PP tests)

Bild 3. Experimenteller Aufbau für Penetration in Sand. Links: oberflächennahe Penetration (SP Versuche), rechts: Pfahlpenetration (PP Versuche)

The main components of the test equipment to investigate pile penetration (PP) into sand are a chamber with glass walls, a half-cylindrical pile prototype with different pile tips, and a jack-in piling device. The complete set-up is shown in Fig. 3 on the right. A welded steel frame forms the chamber structure. The front and rear walls are $1050 \mathrm{~mm} \times 891 \mathrm{~mm}$ panels of laminated sheet glass with a thickness of $2 \times 12 \mathrm{~mm}=24 \mathrm{~mm}$ each. In total, the test chamber has internal dimensions of $1000 \mathrm{~mm} \times 891 \mathrm{~mm} \times 388 \mathrm{~mm}$.

A half-cylindrical pile prototype with three exchangeable tips (conical, flat, hemispherical; see Fig. 4) was manufactured in order to model axisymmetric pile penetration with one glass panel serving as a plane of symmetry. The parts were molded by machining from solid round aluminium bars with a diameter of $D=50 \mathrm{~mm}$. The maximum relative pile penetration depth that can be achieved is $z_{\max } / D \approx 9.0$. The jack-in piling device consists of a pile guide, a worm gear screw jack combined with a worm drive, and a servo motor. The chosen combination results in a penetration velocity of $4.6 \mathrm{~mm} / \mathrm{min}$. A reference scale is attached to the pile guide for pile displacement measurement purposes, and a load cell is placed between the pile head and the load pad of the screw jack (Fig. 3).

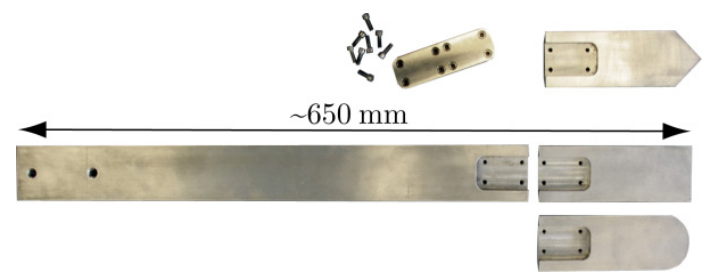

Fig. 4. Half-cylindrical model pile prototype with three different pile tips

Bild 4. Halbzylindrischer Modellpfahl-Prototyp mit drei unterschiedlichen Pfahlspitzen 
The experimental set-ups for the SP and PP tests are supplemented by camera equipment. A Canon PowerShot G5 digital still camera was used throughout the present research. This camera is equipped with a CCD chip providing a maximum resolution of 2592 x 1944 pixels. Two $500 \mathrm{~W}$ halogen floodlights are used to illuminate the soil through the window.

The series of consecutive still images recorded during the tests are analyzed by using the PIV method. PIV is a two-dimensional measuring technique based on image analysis. It was originally developed in the area of experimental fluid mechanics [29] and has recently gained recognition in experimental soil mechanics [27], [28]; GeoPIV [30] is the particular software employed during the present research. The primary objective of the PIV method is the determination of the images of incremental material displacement vectors. To this end, two images from consecutive configurations of the granular body are subdivided into patches, and then the pixel intensities of each pair of patches are cross-correlated. From the field of local incremental displacement vectors obtained, the equivalent shear strain rate or volumetric strain rate can be derived. The correlation procedure is repeated for all patches of an image, and then the subsequent images in the series are processed in the same manner.

\subsection{Test sand and experimental program}

The sand for the model tests is a quartz sand with well-rounded to angular grains identified as finegravelly coarse sand (fgrCSa) according to DIN14688-1. In the conducted tests, the chambers were filled with air-dried test sand by either dry sieve pluviation or dry deposition. Each sand model was prepared in several layers of equal thickness in order to achieve a homogeneous distribution of initial density. The initial mean relative densities of the pluviated sand model were always larger than $D_{\mathrm{r} 0}=75 \%\left(=I_{\mathrm{D} 0}\right)$. When using the dry deposition technique, the sand is placed in thin layers in a low-energy state without any drop height by using a shovel. By this the lowest initial mean relative density achieved was $D_{\mathrm{r} 0}=21 \%$.

Series of shallow penetration and pile penetration model tests have been undertaken with a total of 3 and 28 tests, respectively. Parameters varied during the test series were the initial sample density and the pile tip geometry (only PP tests). Further details concerning the test sand and the experimental program are given in [17].

\subsection{Discussion of test results}

The results of the conducted experimental model tests contain conventionally measured loaddisplacement data as well as incremental soil displacement and strain data for different penetration depths obtained from GeoPIV analysis. However, only a few of the PIV results reported in [17] will be addressed here. In what follows, $z$ denotes the penetration depth, $B$ is the breadth of the foundation in case of shallow penetration, and $D$ is the pile diameter. The incremental penetration which causes the incremental displacement and strain fields in the sand shown in the figures was $\Delta z=2 \mathrm{~mm}$ in case of the SP tests and $\Delta z=2.3 \mathrm{~mm}$ in case of the PP tests.

Three principle modes of shear failure are associated with quasi-static penetration into soil [31], [32], [33], and these modes could also be observed in the present tests: general shear failure, local shear failure, and punching shear failure. Consider, for example, the shallow penetration tests in relatively loose sand (SP-1, $\left.D_{\mathrm{r} 0}=34 \%\right)$ and in relatively dense sand (SP-3, $\left.D_{\mathrm{r} 0}=78 \%\right)$. As can be seen from the PIV results in Fig. 5, shearing of the sand model in both tests is initiated below the outer edges the model foundation immediately after penetration has begun. At continued penetration, shearing localizes and primarily propagates along distinct slip surfaces which encapsulate a wedge-shaped zone immediately below the model foundation. At a relative penetration depth of about $z / B=0.3$, the three characteristic zones associated with general shear failure become apparent. 


\section{geotechnik Article/Report}

The PIV analysis results of the conducted pile penetration tests PP-26-H (hemispherical tip) and PP-27-F (flat-ended tip) in loose sand are shown in Fig. 6. In these tests, in contrast to the pile penetration tests in dense sand, neither global nor local shear failure can be identified. Instead, the penetration process is controlled by punching shear failure in all three depths that have been analyzed. The typical core zone generated immediately under a pile is present at all depths shown. Using the hemispherical tip results in core zone a much smaller than for a flat-ended pile, as it anticipates the core zone to a certain degree.
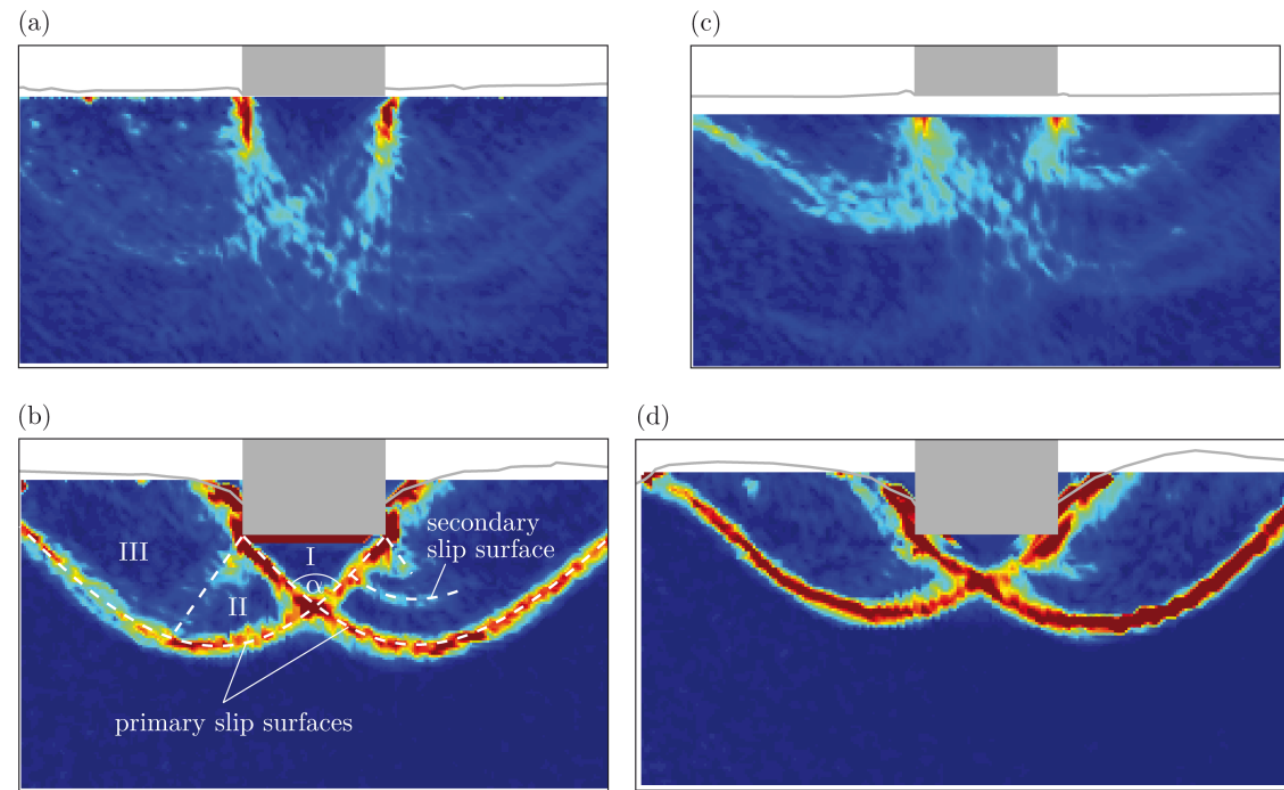

(d)

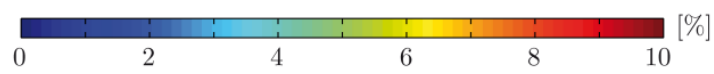

Fig. 5. Incremental maximum shear strain during shallow penetration (SP tests). Left: test SP-1 $\left(D_{\mathrm{r} 0}=34 \%\right)$ at $(a) z / B=0.06$, (b) $z / B=0.33$ with overlaid failure mechanism. Right: test SP-3 $\left(D_{\mathrm{r} 0}=78 \%\right)$ at $(\mathrm{c}) \mathrm{z} / \mathrm{B}=0.01,(\mathrm{~d}) \mathrm{z} / \mathrm{B}=0.31$. The grey line represents the ground surface

Bild 5. Inkrementelle maximale Scherdehnung während der oberflächennahen Penetration (SP Versuche). Links: Versuch SP-1 $\left(D_{\mathrm{r} 0}=34 \%\right)$ bei (a) $\mathrm{z} / \mathrm{B}=0.06$, (b) $\mathrm{z} / \mathrm{B}=0.33$ mit Bruchmechanismus überlagert. Rechts: Versuch SP-3 $\left(D_{\mathrm{r} 0}=78 \%\right)$ bei $(\mathrm{c})$ $z / B=0.01,(d) z / B=0.31$. Die graue Linie repräsentiert die Bodenoberfläche

(a)

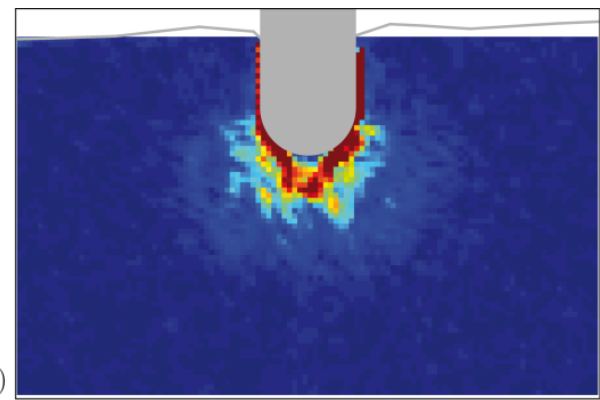

(b)

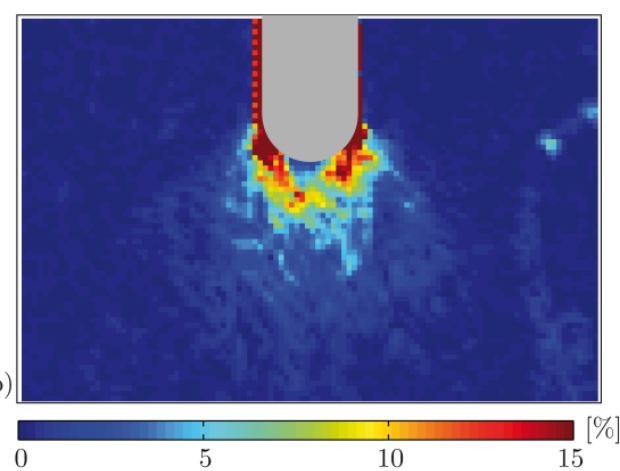

(c)

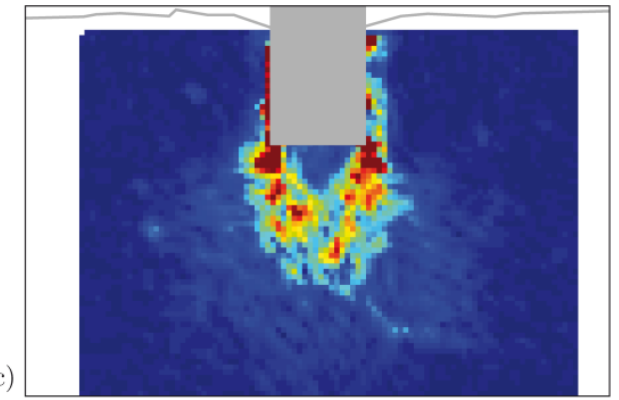

(d)

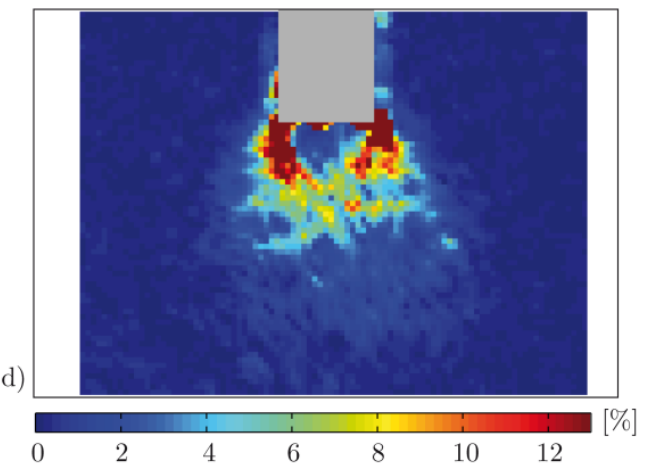

Fig. 6. Incremental maximum shear strain during pile penetration (PP tests). Left: test $P P-26-\mathrm{H}\left(D_{\mathrm{r} 0}=34 \%\right)$ at $(\mathrm{a}) \mathrm{z} / \mathrm{B}=1.4$, (b) $z / B=8.5$. Right: test PP-27-F $\left(D_{r}=21 \%\right)$ at $(c) z / B=1.3,(d) z / B=8.5$. The grey line represents the ground surface 
Bild 6. \%). Inkrementelle maximale Scherdehnung während der Pfahlpenetration (PP Versuche). Links: Versuch PP-26-H $\left(D_{r 0}=34 \%\right.$ ) bei (a) $z / B=1.4$, (b) $z / B=8.5$. Rechts: Versuch PP-27-F ( $D_{r 0}=21 \%$ bei (c) $z / B=1.3$, (d) $z / B=8$.. Die graue Linie repräsentiert die Bodenoberfläche

\section{$4 \quad$ Numerical examples and validation}

The numerical examples presented next have been designed with the intention to back-calculate the results of the experimental shallow penetration test SP-3 and pile penetration test PP-26-H addressed in the previous section. In both examples the assumed initial stress state within the sand is the $K_{0}$-state. It is calculated in an isotropically elastic dummy load step based on the bulk mass density and using a Poisson's ratio of $v=1 / 3\left(K_{0}=0.5\right)$.

The hypoplastic rate constitutive equation with intergranular strain (see Section 2.1) is employed to model the behavior of the test sand. The complete set of hypoplastic material constants for the model test sand is: $\phi_{\mathrm{c}}=31.5^{\circ}, h_{\mathrm{s}}=76500 \mathrm{MPa}, n=0.29, \mathrm{e}_{\mathrm{d} 0}=0.48, \mathrm{e}_{\mathrm{c} 0}=0.78, \mathrm{e}_{\mathrm{i} 0}=0.90, \alpha=0.13, \beta=1.0$, $R=10^{-4}, m_{\mathrm{R}}=5.0, m_{\mathrm{T}}=2.0, \beta_{\mathrm{r}}=0.5, \chi=6.0$. Some of these values were estimated in accordance with [34]. There is a subtlety in the proper determination of the constant $h_{\mathrm{s}}$, referred to as granulate hardness, for very small values of mean effective stress $p^{\prime}$. The conventional procedures to determine the granulate hardness are valid only if the mean effective stress is larger than $20 \mathrm{kPa}$ [34]. For a mean effective stress that tends toward zero near the unloaded ground surface, the conventionally determined $h_{\mathrm{s}}$ should be divided by a sufficiently large number such that $h_{\mathrm{s}}<1000 \mathrm{MPa}$; see [17] for a discussion.

\subsection{Back-calculation of shallow penetration test SP-3}

The model depicted in Fig. 7 used for back-calculation of shallow penetration test SP-3 assumes plain strain conditions and takes advantage of symmetry. The foundation is modeled as rigid and its base is perfectly rough, whereas its sides are perfectly smooth. Fig. $8 \mathrm{a}$ shows the initial mesh and Fig. $7 \mathrm{~b}$ the deformed mesh after smoothing at a relative penetration depth of $z / B=0.31$. When using a purely Lagrangian description or when simple heuristic smoothing algorithms were employed instead of the optimization-based procedure developed by the author, then the calculation terminated just after a few time steps due to element inversion.

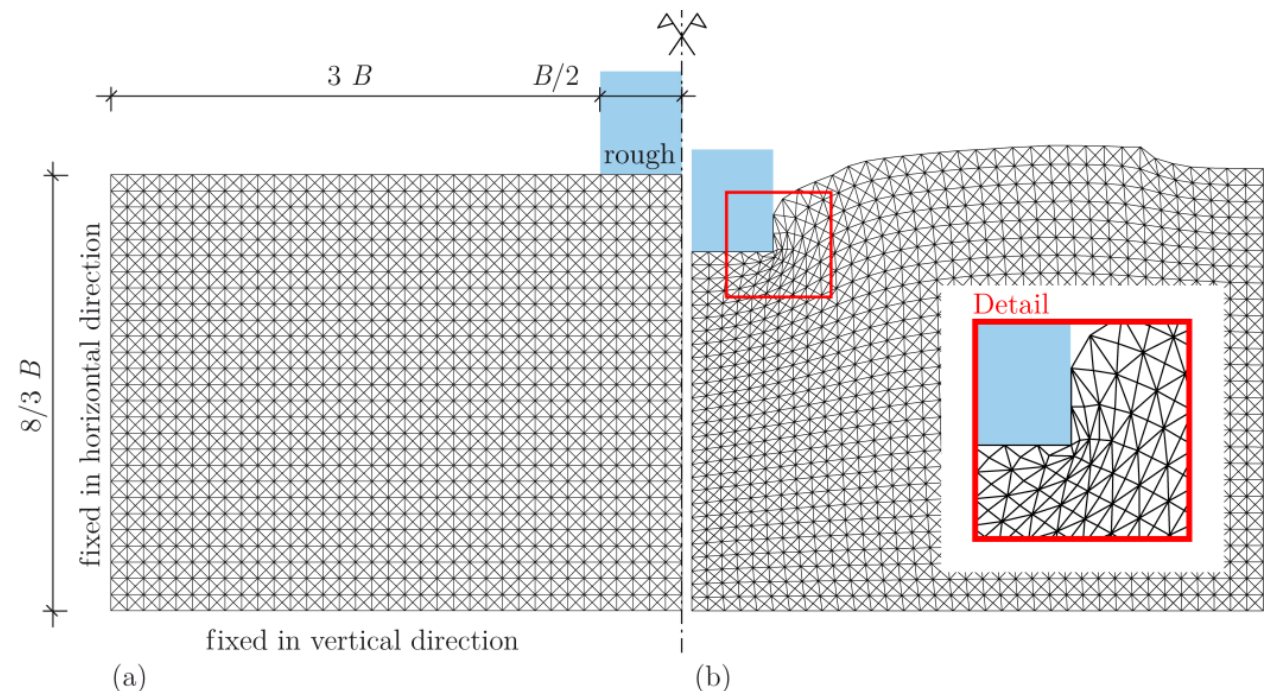

Fig. 7. Shallow penetration into sand. (a) Problem statement and mesh, (b) deformed and smoothed mesh at a relative penetration depth of $z / B=0.31$

Bild 7. Oberflächennahe Penetration in Sand. (a) Problemstellung und Netz, (b) verformtes und geglättetes Netz bei einer relativen Eindringtiefe von $\mathrm{z} / \mathrm{B}=0.31$

The ALE prediction of the void ratio distribution at $z / B=0.31$ is plotted in Fig. 8 . The initial relative density of the sand is $D_{\mathrm{r} 0}=78 \%$ (initial void ratio $e_{0}=0.546$ ), as in the experimental test SP-3. The 
initially dense sand loosens due to shearing lateral to the strip footing and along the slip surfaces within the soil. At the foundation corner, the reached void ratio of $e=0.81$ even lies above the maximum void ratio of $e_{\max }=0.779$ determined through a laboratory test. In the wedge-shaped zone immediately below the foundation, on the other hand, the sand densifies along with penetration and reaches its minimum void ratio of $e_{\min }=0.482$.

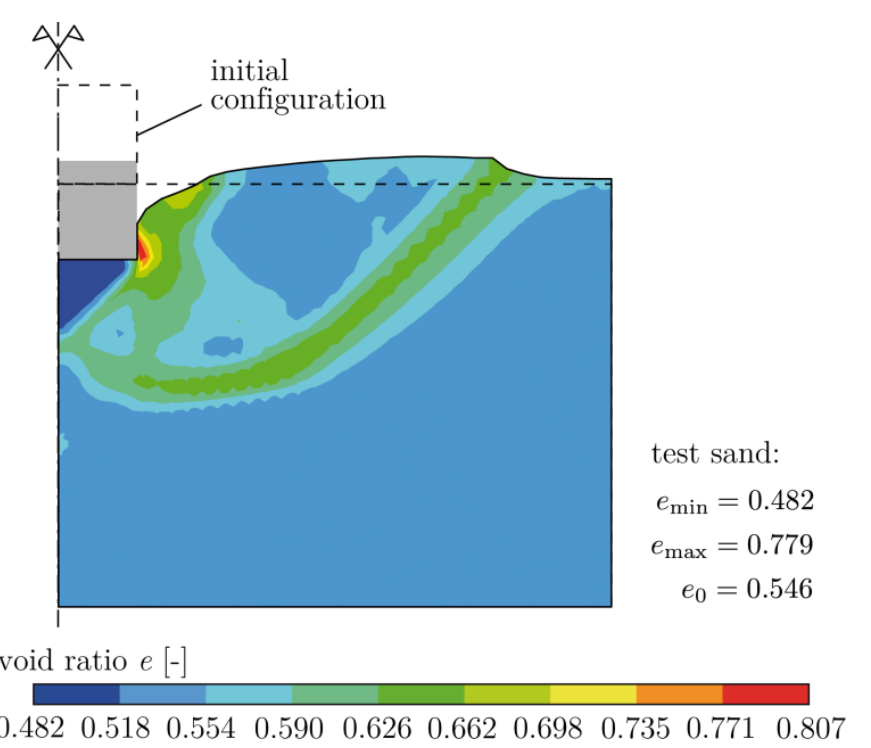

Fig. 8. Shallow penetration into sand. Predicted distribution of the void ratio at $z / B=0.31$

Bild 8. Oberflächennahe Penetration in Sand. Prognostizierte Porenzahlverteilung bei $z / B=0.31$

The ALE simulation is in good agreement with the results of the experimental model test SP-3, as can be seen from the comparative view in Fig. 9 (see also Fig. 5d). The incremental displacement and the zones of maximum shear strain measured within the sand can be fairly reproduced; in fact, the incremental penetration leading to the incremental displacement and strain fields was $\Delta z_{\text {exp }}=2 \mathrm{~mm}$ in case of the SP3 test but only $\Delta z_{\text {num }}=1.2 \mathrm{~mm}$ in the numerical simulation. The measured and the predicted ground heaving also match very well. Differences are found, however, in the shape of wedge underneath the pile base. The angle at the apex of this zone is exactly $90^{\circ}$ in the simulation, whereas the experimental investigation indicates much larger angles.

It is emphasized that the accurate prediction of ground heaving in sand is related to the capability of the constitutive equation to model dilatancy. Concerning the hypoplastic rate constitutive equation used here, dilatancy is not modeled by a separate function but is strongly influenced by the value of the granulate hardness. In the present example, $h_{\mathrm{s}} / 1000$ has been set to obtain the results shown in Figs. 7 to 9 , where $h_{\mathrm{s}}=76500 \mathrm{MPa}$ denotes the value of granulate hardness for the test sand determined by using the conventional procedure [34]. Ground heaving was overestimated when assigning the value $h_{\mathrm{s}} / 100$ instead. However, in this latter case the predicted load-displacement curve is very close to the experimental data (Fig. 10). 
Experiment

ALE Simulation

(a)

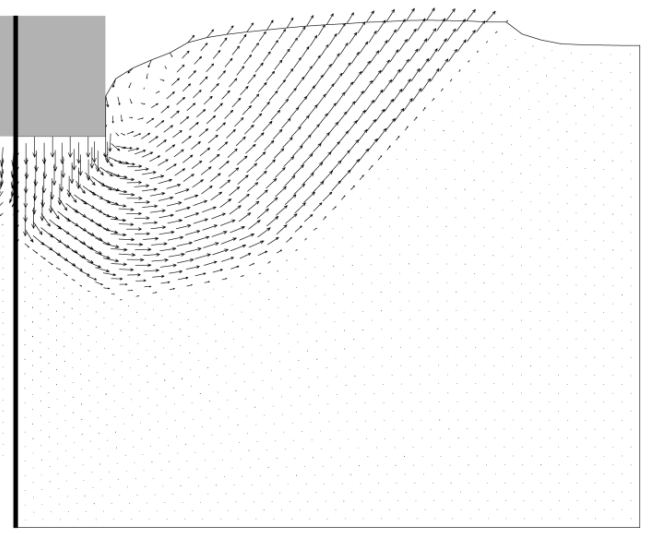

Experiment

ALE Simulation

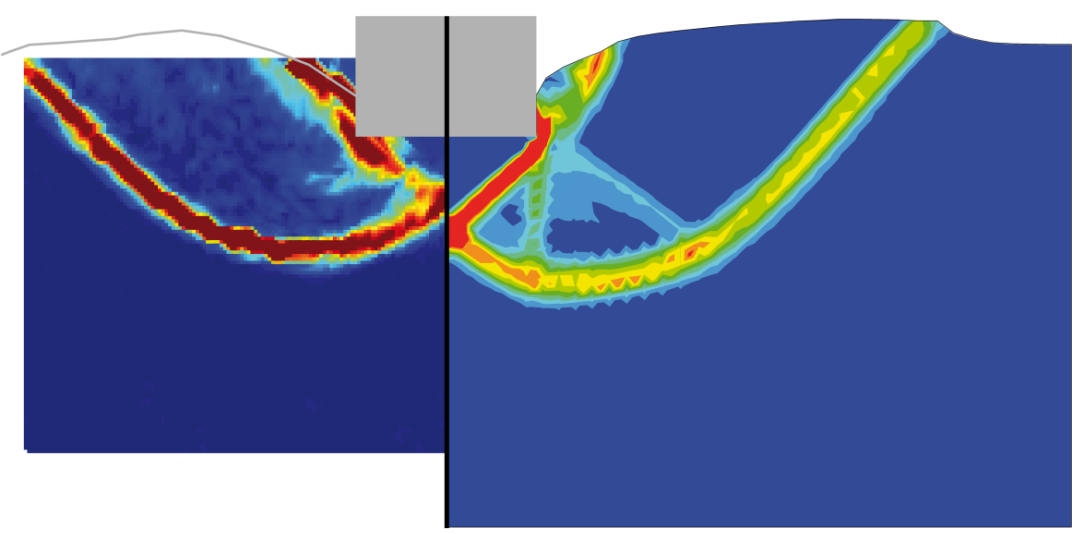

low

high

(b)

Fig. 9. Comparison of the results of experimental test SP-3 and ALE simulation at $z / B=0.31$. (a) Incremental displacement, (b) incremental maximum shear strain

Bild 9. Vergleich der Ergebnisse des Versuchs SP-3 und der ALE Simulation bei $z / B=0.31$. (a) Inkrementelle Verschiebung, (b) inkrementelle maximale Scherdehnung

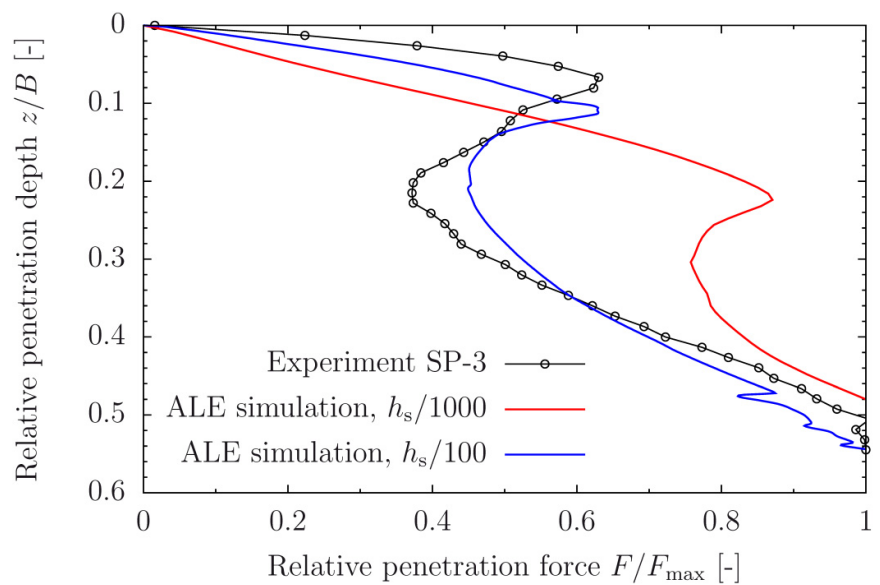

Fig. 10. Comparison of the measured and predicted load-displacement curves for test SP-3

Bild 10. Vergleich der gemessenen und prognostizierten Lastsetzungskurven für Versuch SP-3

\subsection{Back-calculation of pile penetration test PP-26-H}

The computational model for the back-calculation of pile penetration test PP-26-H in loose sand $\left(D_{\mathrm{r} 0}=34 \% ; e_{0}=0.678\right)$ employs the pilot-hole or zipper-type modeling technique. This widely-used 
technique was originally developed to limit mesh distortion in purely Lagrangian calculations. In the axisymmetric models set up here (Fig. 11), the "pile" is designed as a segment of a rigid and perfectly smooth slideline supporting the soil in the direction normal to the slideline.

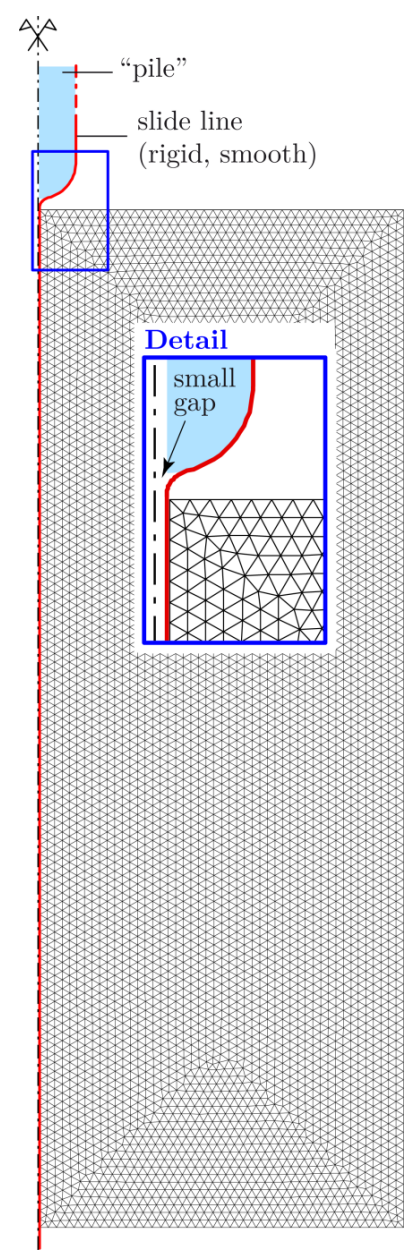

Fig. 11. Pile penetration into sand. Problem statement and initial unstructured coarse mesh

Bild 11. Pfahlpenetration in Sand. Problemstellung und unstrukturiertes grobes Netz im Ausgangszustand

Three finite element models were built which only differ in the meshes defining the body of sand. The dimensions of the computational domain in all three models are $250 \mathrm{~mm} \times 700 \mathrm{~mm}$, which complies with the configuration of the experimental test. One unstructured and two structured uniform finite element meshes (not shown in Fig. 11) were generated. The granulate hardness material constant assigned to the test sand was $76.5 \mathrm{MPa}=h_{\mathrm{s}} / 1000$ in all three numerical models.

Calculated void ratio distributions using the structured fine mesh are plotted in Fig. 12; the minimum and maximum void ratio of the test sand determined through laboratory tests are $e_{\min }=0.482$ and $e_{\max }=0.779$, respectively. Fig. 12 indicates a significant densification of the sand immediately underneath the pile base at all stages of penetration. At a relative penetration depth of $z / D=8.5$, the maximum relative density reaches $D_{\mathrm{r}}=68 \%$. The pile shaft is surrounded by a zone of severe loosening during the course of penetration. The zone of maximum loosening possesses a void ratio of about $e=0.81>e_{\max }$ and is located between $0.5 \mathrm{D}$ and $1.0 \mathrm{D}$ below the ground surface irrespective of the penetration depth. 

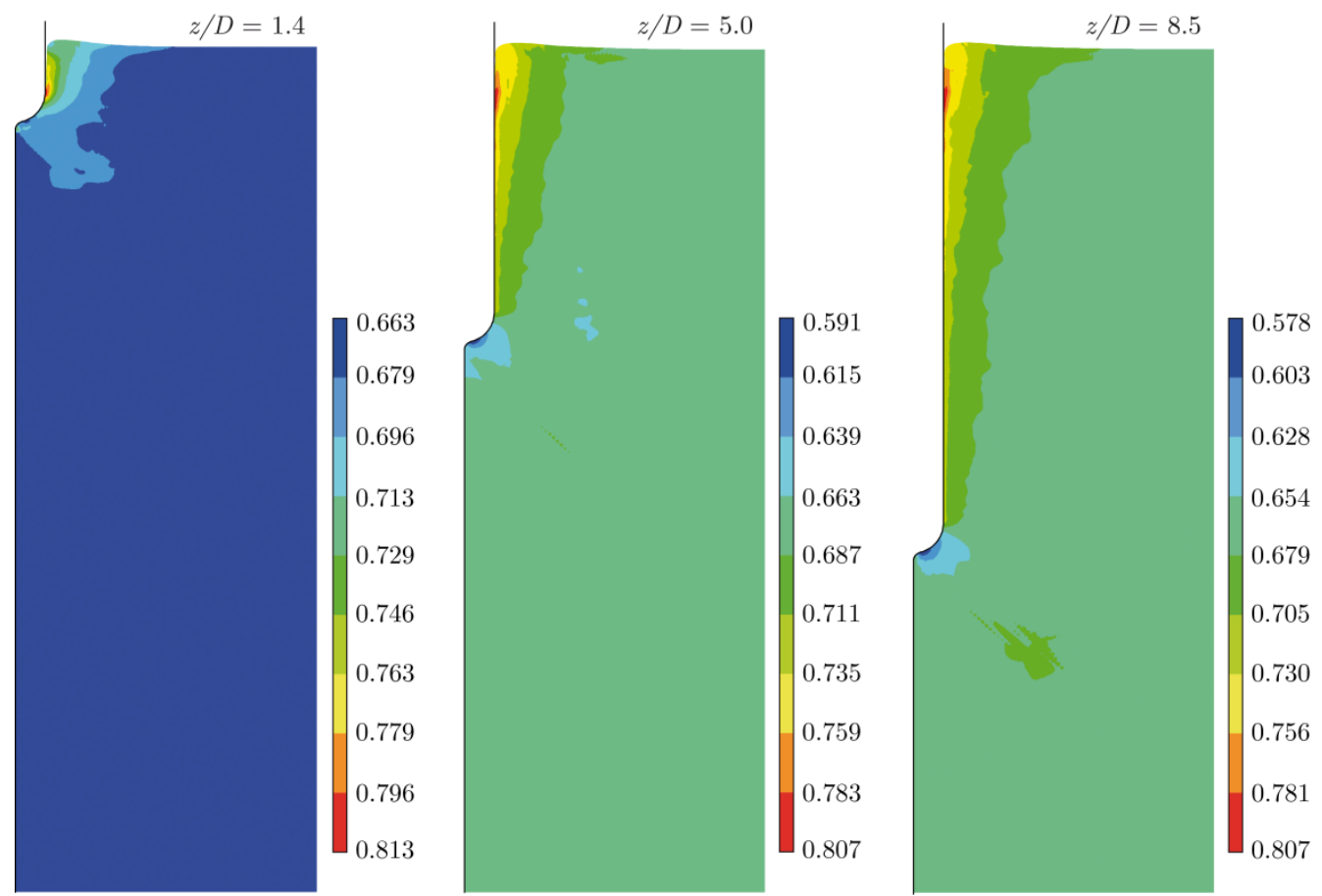

Fig. 12. Pile penetration into sand. Void ratio distributions at different penetration depths (initial void ratio $e_{0}=0.678$ )

Bild 12. Pfahlpenetration in Sand. Porenzahlverteilung in verschiedenen Penetrationstiefen (Ausgangsporenzahl $e_{0}=0.678$ )

In Fig. 13, the measured and simulated incremental maximum shear strains of test PP-26-H are compared. Comparison is only qualitative because the plotted incremental strain fields resulted from different incremental displacement of the pile, which was $\Delta z_{\exp }=2.3 \mathrm{~mm}$ in the test but only $\Delta z_{\text {num }}=0.5 \mathrm{~mm}$ in the numerical simulation. At $z / D=1.4$, the measured and the predicted ground heaving match very well. Moreover, in all three depths shown the ALE simulation reproduces the peak of incremental maximum shear strain located where the sand is flowing around the hemispherical pile tip. The small wedge-shaped dead zone formed underneath the pile base in the experiment, however, is not present in the backcalculation. Such a zone is a manifestation of arching effects due to surface roughness. Hence, the comparison in Fig. 13 suggests that the assumption of a perfectly smooth surface of the pile tip in the numerical model does not correspond to reality.

The measured and predicted load-displacement curves of pile penetration test PP-26- $\mathrm{H}$ are in a reasonably good agreement (Fig. 14). However, the curves considerably differ in relative penetration depths of $1<z / D<5$. The difference at small penetration depths is related to the undesired restraining forces in the experimental set-up not accounted for in the numerical model as well as to the problem of modeling the behavior of sand at very low effective stress levels. The latter has been discussed within the context of the previous example (Section 4.1). In larger depths, the predicted load-displacement curves show a characteristic zig-zag form depending on the spatial approximation of the pile-soil contact interface. This problem is well-known [35] and is caused by the periodical release of the finite element nodal forces whenever a node loses contact with the pile skin. For the unstructured coarse mesh, which corresponds to the worst interface discretization, the frequency of spurious oscillation is very low but its mean amplitude is the largest of all three meshes considered. 


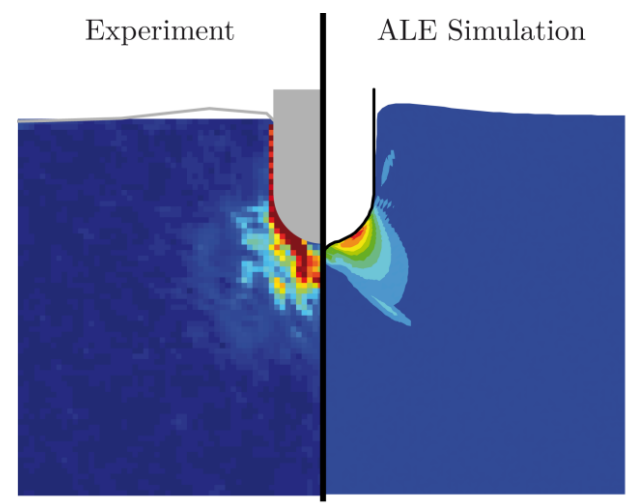

(a) $z / D=1.4$

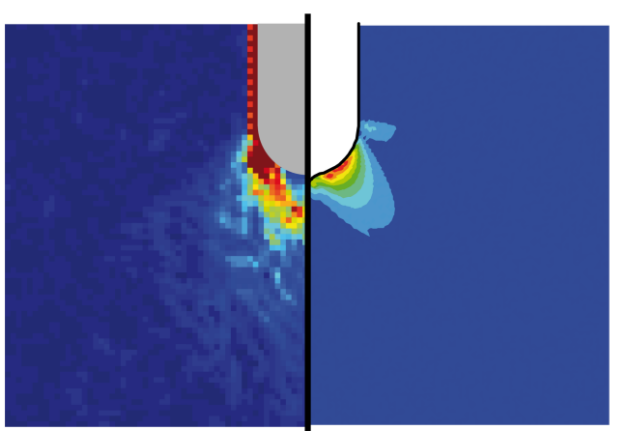

(c) $z / D=8.5$

Fig. 13. Comparison of the measured (left) and simulated (right) incremental maximum shear strain at different penetration depths Bild 13. Vergleich der gemessenen (links) und prognostizierten (rechts) inkrementellen maximalen Scherdehnung in verschiedenen Penetrationstiefen

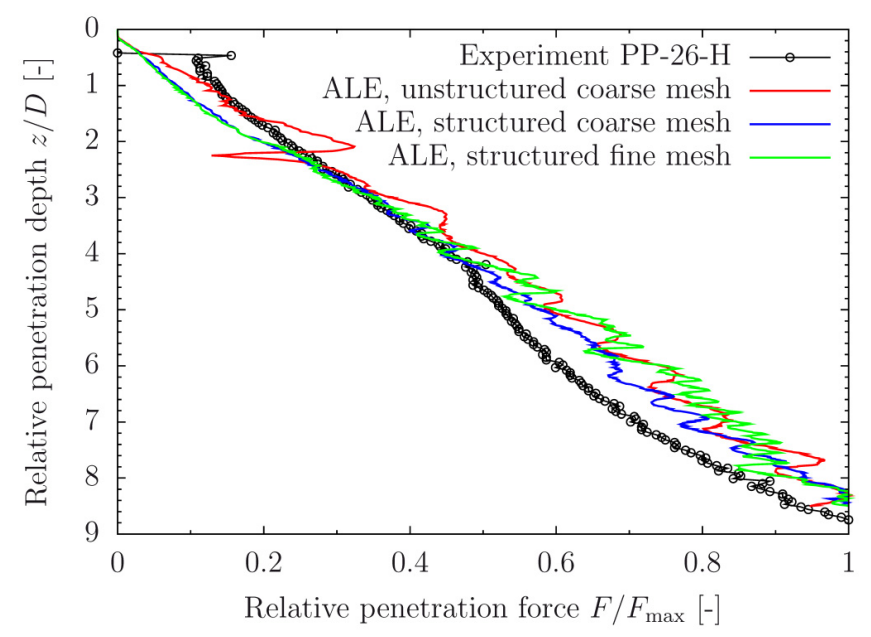

Fig. 14. Comparison of the measured and predicted load-displacement curves for test PP-26-H

Bild 14. Vergleich der gemessenen und prognostizierten Lastsetzungskurven für Versuch PP-26-H

\section{Conclusions and outlook}

An ALE finite element method for the numerical simulation of large deformation problems in soil mechanics has been presented and validated through experimental model tests. Unique features of the method are an advanced hypoplastic rate constitutive equation for sand and an efficient and robust optimization-based mesh smoothing algorithm which restores the quality even of indented (i.e. non-convexly distorted) mesh regions. The experimental model tests were concerned with the quasi-static penetration of model foundations and model piles into sand at different initial densities. Based on the image sequences recorded during these tests, application of particle image velocimetry has enabled indirect meas- 
urement of deformation time histories. The tests have revealed interesting details of the processes despite the lack of a thorough quantification.

Generally speaking, the experimental results and the results obtained through ALE finite element simulations are in good agreement. Shear zones observed within the sand can be fairly reproduced. The measured and predicted load-displacement curves, however, may differ considerably in depths of less than one and more than five times the diameter of the penetrator. It has been found that the difference at small penetration depths is closely related to the modeled material behavior and the fact that the mean effective stress tends to zero at the unloaded ground surface. Under such conditions the shear strength of a granular solid cannot be reliably computed by using common soil mechanical models. As a result, it was possible to adjust the set of material constants of the hypoplastic rate constitutive equation such that either the load-displacement curve or the soil heaving matched the experimental results at small penetration depth, but not both.

The rigorous modeling of penetration into sand is very difficult because of the strong nonlinearities due to complex material behavior, large deformations, contact constraints, and the large variation of the soil stiffness at the unloaded ground surface and underneath the penetrator. Owing to these strong nonlinearities, stable and robust numerical simulations are usually hard to achieve and prove to be computationally intensive; the back-calculation of pile penetration test PP-26-H took several days on a workstation. However, these issues primarily arise from the Lagrangian step and not from the mesh motion or transport steps of the ALE method. In the numerical examples shown, the computational effort needed for mesh smoothing and advection was outbalanced by the implicit Lagrangian calculation which required very small time steps with ten to hundreds of global equilibrium iterations per step.

The difficulties and computational complexity associated with soil penetration are shared by ALE and other numerical methods (e.g. CEL) allowing for large material deformations. They require careful judgment of the user and render the simulation of real-world problems almost impracticable. However, such simulations are important for research and development purposes as they provide valuable insight into soil behavior and change of soil state during penetration. Results of the simulations can then be used, for example, to derive recommendations for practice how to adjust the initial soil stress and density state in traditional FE models so as to account for the penetration process, but without using advanced ALE or related methods.

The assumptions and restrictions associated with the ALE method presented in this paper give motivation to further research. Improvements and extensions include the incorporation of inertia effects to solve transient problems, the provision for surface roughness in the contact model at the soil-penetrator interface, and a description of the soil interacting with one or more pore fluids. The extension to a so-called multi-material ALE (MMALE) approach is investigated by the author within the scope of a subproject of the DFG Research Unit FOR 1136 [36], [37].

\section{Acknowledgement}

The financial support from the German Research Foundation (DFG), grants SA 310/21-1 and SA 310/212 is gratefully acknowledged. In addition, I want to thank Prof. Stavros A. Savidis, TU Berlin, for giving me the opportunity to work on this interesting topic and for guiding and supporting me during my research work, as well as my former colleague Prof. Frank Rackwitz, OTH Regensburg, for several fruitful discussions.

\section{Bibliography}

[1] Benson, D. J.: Computational Methods in Lagrangian and Eulerian Hydrocodes. Comput. Meth. Appl. Mech. Eng. 99 (1992), pp. 235-394. 
[2] Qiu, G., Grabe, J.: Explicit Modeling of Cone and Strip Footing Penetration under Drained and Undrained Conditions using a Visco-Hypoplastic Model. Geotechnik 34 (2011), pp. 205-217.

[3] Jiang, M. J., Yu, H.-S., Harris, D.: Discrete Element Modelling of Deep Penetration in Granular Soils. Int. J. Numer. Anal. Methods Geomech. 30 (2006), pp. 335-361.

[4] Obermayr, M., Vrettos, Ch.: Anwendung der Diskrete-Elemente-Methode zur Vorhersage von Kräften bei der Bodenbearbeitung. Geotechnik 36 (2014), pp. 231-242.

[5] Beuth, L.: Formulation and Application of a Quasi-Static Material Point Method. Dissertation, Fakultät für Bau- und Umweltingenieurwissenschaften, Universität Stuttgart, 2012.

[6] Al-Kafaji, I. K. J.: Formulation of a Dynamic Material Point Method (MPM) for Geomechanical Problems. Dissertation, Fakultät für Bau- und Umweltingenieurwissenschaften, Universität Stuttgart, 2013.

[7] Bui, H. H., Fukagawa, R., Sako, K., Wells, J. C.: Slope Stability Analysis and Discontinuous Slope Failure Simulation by Elasto-Plastic Smoothed Particle Hydrodynamics (SPH). Géotechnique 61 (2011), pp. 565-574.

[8] Grabe, J., Stefanova, B.: Numerical Modeling of Saturated Soils, Based on Smoothed Particle Hydrodynamics (SPH). Part 1: Seepage Analysis. Geotechnik 37 (2014), pp. 191-197.

[9] Henke, S., Qiu, G., Grabe, J.: A Coupled Eulerian-Lagrangian Approach to Solve Geotechnical Problems Involving Large Deformations. Proc. 7th Eur. Conf. Numer. Meth. Geotechn. Eng. (NUMGE 2010), CRC Press, London, 2010, pp. 233-238.

[10] Tho, K. K., Leung, C. F., Chow, Y. K., Swaddiwudhipong, S.: Eulerian Finite-Element Technique for Analysis of Jack-Up Spudcan Penetration. Int. J. Geomech. 12 (2012), pp. 64-73.

[11] Di, Y., Yang, J., Sato, T.: An Operator-Split ALE Model for Large Deformation Analysis of Geomaterials. Int. J. Numer. Anal. Methods Geomech. 31 (2007), pp. 1375-1399.

[12] Sheng, D., Nazem, M., Carter, J. P.: Some Computational Aspects for Solving Deep Penetration Problems in Geomechanics. Comput. Mech. 44 (2009), pp. 549-561.

[13] Savidis, S. A., Aubram, D., Rackwitz, F.: Arbitrary Lagrangian-Eulerian Finite Element Formulation for Geotechnical Construction Processes. J. Theor. Appl. Mech. 38 (2008), pp. 165-194.

[14] Aubram, D., Rackwitz, F., Savidis, S. A.: An ALE Finite Element Method for Cohesionless Soil at Large Strains: Computational Aspects and Applications. Proc. 7th Eur. Conf. Numer. Meth. Geotechn. Eng. (NUMGE 2010), CRC Press, London, 2010, pp. 245-250.

[15] Aubram, D., Rackwitz, F., Wriggers, P., Savidis, S. A.: An ALE Method for Penetration into Sand Utilizing Optimization-Based Mesh Motion. Computers and Geotechnics 65 (2015), pp. 241-249. doi:10.1016/j.compgeo.2014.12.012.

[16] Aubram, D.: Über die Berücksichtigung großer Bodendeformationen in numerischen Modellen. Ohde-Kolloquium, Dresden, 2014, pp. 109-122. http://nbn-resolving.de/urn:nbn:de:bsz:14-qucosa-139883

[17] Aubram, D.: An Arbitrary Lagrangian-Eulerian Method for Penetration into Sand at Finite Deformation. Shaker, Aachen, 2013 (Veröffentlichungen des Grundbauinstitutes der Technischen Universität Berlin, Heft 62). http://opus4.kobv.de/opus4-tuberlin/frontdoor/index/index/docId/4755

[18] Aubram, D.: Differential Geometry Applied to Continuum Mechanics. Shaker, Aachen, 2009 (Veröffentlichungen des Grundbauinstitutes der Technischen Universität Berlin, Heft 44). http://opus4.kobv.de/opus4-tuberlin/frontdoor/index/index/docId/2159

[19] von Wolffersdorff, P.-A.: A Hypoplastic Relation for Granular Materials with a Predefined Limit State Surface. Mech. Cohes. Frict. Mat. 1 (1996), pp. 251-271.

[20] Niemunis, A., Herle, I.: Hypoplastic Model for Cohesionless Soils with Elastic Strain Range. Mech. Cohes. Frict. Mat. 2 (1997), pp. 279-299.

[21] Belytschko, T., Liu, W. K., Moran, B.: Nonlinear Finite Elements for Continua and Structures. John Wiley \& Sons, 2000.

[22] Simo, J. C., Hughes, T. J. R.: Computational Inelasticity. Springer-Verlag, Berlin, 1998.

[23] Aymone, J. L. F., Bittencourt, E., Creus, G. J.: Simulation of 3D Metal-Forming Using an Arbitrary Lagrangian-Eulerian Finite Element Method. J. Mater. Process. Technol. 110 (2001), pp. $218-232$.

[24] Aubram, D.: Optimization-Based Smoothing Algorithm for Triangle Meshes Over Arbitrarily Shaped Domains. arXiv:1410.5977 [cs.NA], 2014.

[25] LeVeque, R. J.: Finite Volume Methods for Hyperbolic Problems. 3rd ed., Cambridge University Press, 2002.

[26] Linder, W.-R.: Zum Eindring- und Tragverhalten von Pfählen in Sand. Dissertation, Fachbereich 
für Bauingenieur- und Vermessungswesen, Technische Universität Berlin, 1977.

[27] White, D. J.: An Investigation into the Behaviour of Pressed-In Piles. Dissertation, University of Cambridge, 2002.

[28] White, D. J., Take, W. A., Bolton, M. D.: Soil Deformation Measurement Using Particle Image Velocimetry (PIV) and Photogrammetry. Géotechnique 53 (2003), pp. 619-631.

[29] Adrian, R. J.: Particle-Imaging Techniques for Experimental Fluid Mechanics. Annu. Rev. Fluid Mech. 23 (1991), pp. 261-304.

[30] White, D. J., Take, W. A.: GeoPIV: Particle Image Velocimetry (PIV) Software for Use in Geotechnical Testing. Technical Report CUED/D-SOILS/TR322, University of Cambridge, 2002.

[31] Terzaghi, K.: Theoretical Soil Mechanics. John Wiley \& Sons, New York, 1943.

[32] Vesic, A. S.: Analysis of Ultimate Loads of Shallow Foundations. ASCE J. Soil Mech. Found. Div. 99 (1973), pp. 45-73.

[33] Craig, R. F.: Craig's Soil Mechanics. 7th ed., Spon Press, London, 2007.

[34] Herle, I., Gudehus, G.: Determination of Parameters of a Hypoplastic Constitutive Model from Properties of Grain Assemblies. Mech. Cohes. Frict. Mat. 4 (1999), pp. 461-486.

[35] Simo, J. C., Meschke, G.: A New Class of Algorithms for Classical Plasticity Extended to Finite Strains. Application to Geomaterials. Comput. Mech. 11 (1993), pp. 253-278.

[36] Aubram, D., Rackwitz, F., Savidis, S. A.: Investigation of Vibro-Injection Pile Installation in Sand: Part I-Interpretation as Multi-Material Flow. In: Th. Triantafyllidis (ed.) Holistic Simulation of Geotechnical Installation Processes. Springer International Publishing Switzerland 2015 (to be published).

[37] Savidis, S. A., Aubram, D., Rackwitz, F.: Investigation of Vibro-Injection Pile Installation in Sand: Part II-Numerical and Experimental Investigation. In: Th. Triantafyllidis (ed.) Holistic Simulation of Geotechnical Installation Processes. Springer International Publishing Switzerland 2015 (to be published).

\section{Author:}

Dr.-Ing. Daniel Aubram

Technische Universität Berlin (TU Berlin)

Chair of Soil Mechanics and Geotechnical Engineering

Secr. TIB1-B7, Gustav-Meyer-Allee 25

13355 Berlin

Email: daniel.aubram@tu-berlin.de 